\title{
MENDES, J. R.; SYLLA, B. J. TECNOFILOSOFIA LÍQUIDA: Anders, Blumenberg e Sloterdijk. Braga: Centro de Ética, Política e Sociedade, 2019
}

\section{Luis Gabriel Provinciatto ${ }^{1}$}

MENDES, J. R.; SYLLA, B. J. Tecnofilosofia líquida: Anders, Blumenberg e Sloterdijk. Braga: Centro de Ética, Política e Sociedade, 2019.

Tecnofilosofia líquida é um livro composto por duas partes: na primeira, João Ribeiro Mendes e Bernhard Josef Sylla oferecem traduções de textos de Günther Anders (1902-1992), Hans Blumenberg (1920-1996) e Peter Sloterdijk (1947), a respeito da técnica e da tecnologia; na segunda, juntamente com Felizardo Pedro, disponibilizam quatro textos críticos (três em inglês e um em português) a respeito desses mesmos autores, com o propósito de não só fazer um comentário, mas também de apontar problemas, formular críticas, indicar desdobramentos e prospectivas. Nesse sentido, o(a) leitor(a) encontrará, na segunda parte, posições para além das mais comuns, a saber: que Anders é um tecnofóbico, que Sloterdijk é um entusiasta da técnica e da tecnologia e que Blumenberg é alguém de duplo posicionamento, ora defendendo, ora condenando o uso da tecnologia, em seus ganhos e potenciais riscos.

O primeiro conjunto de textos traduzidos é de Günther Anders e conduz a três capítulos de sua obra A obsolescência do homem: sobre a destruiçáa da vida na época da terceira Revolução Industrial (1992). O primeiro a ser apresentado - A obsolescência do trabalho (1977) - aborda a ausência de liberdade do proletário, cuja origem remonta às esteiras/linhas de montagem e cujo ápice se dá com a automatização das fábricas, que faz do proletário não

\footnotetext{
${ }^{1}$ Universidade Federal de Juiz de Fora, Juiz de Fora, MG - Brasil e Universidade de Évora, Évora Portugal. https://orcid.org/0000-0003-0597-8641 Email: lgprovinciatto@hotmail.com.
}

https://doi.org/10.1590/0101-3173.2021.v44dossier.14.p257

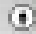

This is an open-access article distributed under the terms of the Creative Commons Attribution License. 
mais um "trabalhador", senão um "pastor do objeto", ou melhor, um guardião da máquina, a responsável por produzir. Cabe ao guardião supervisioná-la, aguardando, no limite, que "nada aconteça" (ANDERS, 2019, p. 12). Do ponto de vista político-econômico, são necessários menos empregados para se produzir mais, logo, a lógica de racionalização dos meios de produção presente no capitalismo não permite haver pleno emprego. A privação do trabalho $\mathrm{e}$, posteriormente, do emprego, não é, a princípio, um fato político, mas um efeito da constante revolução tecnológica, a qual, de acordo com Anders, é a única que acontece independentemente dos sistemas políticos.

Adiante, $A$ obsolescência das máquinas, cuja primeira parte foi escrita em 1960 e a segunda em 1969, focaliza uma ontologia das máquinas, cuja proposta fundamental é, a partir da coordenação de macro e micro aparelhos, incorporá-las em um único aparelho regulador, no qual tudo funciona. Em outras palavras: a ideia é transformar o universo numa única máquina, fazendo do mundo um espaço de ocupação virtual, onde tudo se torna material requisitável para alimentar essa única máquina. Com isso, cinco características ontológicas são apresentadas: o caráter expansivo das máquinas, pois nesse processo elas incluem o mundo circundante que lhes é próprio; a insaciedade desse caráter expansivo, de tal modo que uma máquina tende a incorporar outra, mais outra e assim por diante; a diminuição do número de máquinas, não no sentido fatual, mas no de que o conjunto tende à unicidade; o decaimento da máquina, a qual, em sentido ontológico, deixa de ser "máquina" e passa a ser peça de máquinas maiores; por fim, ao estilo dialético hegeliano, a máquina é superada e convertida em peça, ou melhor, assumida como peça de uma única máquina.

Justamente aqui se percebe a vocação totalitária da revolução tecnológica: os microaparelhos se subjugam ao macroaparelho, com vistas ao perfeito funcionamento. Isso, contudo, representa um risco, pois "quanto maior é a grande máquina, mais seriamente se encontram ameaçadas as suas peças, que haviam funcionado individualmente antes de se unirem." (ANDERS, 2019, p. 30). Há perigo, porque o mau funcionamento de um dos microaparelhos pode acarretar um enorme dano no macro. De tal modo, a integração das partes com o todo e deste com aquelas não isenta a ambos de uma proteção recíproca, estando a parte protegida quando o todo falhar e vice-versa. Quanto maior a máquina, maior o perigo de um colapso, donde a necessidade de um planejamento ou, de acordo com Anders, de um "doseamento da magnitude 
das grandes máquinas" (ANDERS, 2019, p. 33). Esse doseamento é, sem dúvida, uma tarefa política.

Contudo, esse problema não admite uma resposta unívoca, pois, no limite, não se trata da regulação do bom ou mau uso da técnica e da tecnologia, mas do fato de já náo dispormos livremente dela. No limite, o maior perigo não é a má utilização, todavia, a própria essência dominadora e totalitária da técnica, de sorte que "resulta difícil responder à pergunta sobre onde é que terá de cessar o sim à técnica e onde é que terá de começar o não, pois esta converte-se numa ameaça não só onde se converte na técnica da ameaça.” (ANDERS, 2019, p. 34).

O último texto de Anders, $A$ obsolescência da história, é composto por três partes, escritas em 1978. A primeira parte aborda a técnica como sujeito da história, não só justificando a substituiçáo do ser humano como sujeito da história pela técnica, porém, sobretudo, demonstrando que ela é a meta da história. Aqui, Anders se ocupa em apresentar a condição de permanência, ou melhor, de existência da humanidade: a de ser consumidora de produtos, evidenciando, com isso, que ela está subjugada à máquina, da qual é ou virá a ser parte.

A segunda parte trata da obsolescência da categoria "modernidade", não tanto no sentido filosófico, mas a partir do embate ideológico entre Oeste (capitalismo) e Leste (socialismo): para os soviéticos, a não modernidade está atrelada à rejeiçáo dos não progressistas do Ocidente, ao passo que os do Oeste rejeitam os "contemporâneos" que ainda usam a ideia de "progresso" indiscriminadamente.

Por fim, a terceira parte examina a ideia de publicidade no Ocidente e no Leste europeu, mostrando como, para o primeiro, trata-se de um "mundo de sereias", que, a partir da quebra do tabu sexual, estimula o consumo em funçáo de propagandas com peitos e pernas, ao passo que, para o segundo, a publicidade tem a finalidade de exaltar e dar visibilidade aos instrumentos de intimidação, aos mentores do socialismo e aos dirigentes de Estado.

O segundo texto traduzido, Algumas dificuldades de escrever uma história do espirito da técnica, de Hans Blumenberg, corresponde ao primeiro capítulo de sua obra História do espirito da técnica (2009). A principal pergunta a lhe ser colocada é: apontar algumas (três, na verdade) dificuldades para escrever uma história do espírito da técnica já não é lançar as linhas gerais para tal empreitada? Para tanto, a primeira constatação feita pelo autor é que a história da técnica 
não coincide com a história do espírito da técnica, cujo objetivo é "tornar compreensível de que classe de impulsos surgiram a organização de uma nova realidade antes dos seus próprios elementos poderem apresentar as exigências do seu desenvolvimento e integração interior." (BLUMENBERG, 2019, p. 71). O tema da história (do espírito) da técnica diz respeito, sobretudo, à saída da técnica do âmbito da história, ou seja, de como se passou a compreender a realidade desde outra perspectiva. Justamente nisso reside o problema, pois os relatos, principalmente acerca das origens da mecanização, nos séculos XVII e XVIII, deixam dúvidas a respeito do transfundo da origem da técnica, ou seja, falam da história da técnica, mas não propriamente da história do espírito da técnica.

Em vista desse pressuposto, Blumenberg cita três exemplos para demonstrar essa dificuldade: o primeiro concerne ao conceito de invenção, o segundo à representação do que é a lei natural e o terceiro ao interesse histórico pela técnica, um interesse que compete sempre com outro, a saber, o antropológico. A partir, sobretudo, do terceiro exemplo, Blumenberg conclui que não é possível levar a cabo uma história universal do espirito da técnica, porque seu material histórico deve ser analisado caso a caso, não sendo permitida "uma clara coordenação entre fatores intelectuais e circunstâncias materiais, conforme ao esquema, por exemplo, de infraestrutura e superestrutura, motivaçóes e consequências, projeto e realização." (BLUMENBERG, 2019, p. 84).

O terceiro texto traduzido, O Antropoceno - Estado de um processo à margem da história da Terra? (2016), de Peter Sloterdijk, não se mostra contrário à técnica e à tecnologia, embora também não revele uma cegueira entusiástica favorável às mudanças ocasionadas pela exploração da natureza. Em suma, constitui um trabalho que tende à mediação dos dois radicais, a saber, dos minimalistas do consumo e dos esbanjadores, mas que, ao final, tende a destacar o aspecto positivo da técnica. Isso pode ser claramente percebido na cunhagem do termo homeotécnica, em contraposição a alotécnica: esta é devastadora da Terra, aquela integra homem e natureza, não abdicando da técnica.

Essa perspectiva é moldada com base em uma crítica ao termo/categoria Antropoceno, o qual, de acordo com Sloterdijk, é cunhado com os moldes das eras geológicas do século XIX, cuja construção narrativa se baseava em eras já finalizadas. O Antropoceno, ao contrário, descreve e, portanto, narra a era vigente, cuja base está assentada em uma lógica apocalíptica, que "indica o 
fim da despreocupação cosmológica que constitui o fundamento das formas históricas do estar-no-mundo humano." (SLOTERDIJK, 2019, p. 95). Tratase, na verdade, de um termo/categoria mais alertador que descritor de uma era geo-histórica. Por isso, atrelada ao Antropoceno, surge a necessidade de um conhecimento prognóstico, "algo inédito na história da didática" (SLOTERDIJK, 2019, p. 99), que seja capaz de perceber e formular limites e mudanças na relação entre o ser humano e a Terra, já que a própria ideia de Antropoceno traz consigo só uma minima moralia, própria à época presente.

Traumatology and Technology - On Sloterdijk and Anders, de Bernhard Sylla, abre a sessão de textos críticos. Seu principal objetivo é mostrar a contribuição de Sloterdijk e Anders para o estabelecimento de uma tecnoética líquida, embora o termo em si seja pouco explorado pelo autor. Para tanto, em primeiro lugar, descreve-se brevemente o conceito de traumatologia e como ele pode ser abordado desde três perspectivas (psicológica, sociológica e filosófica), as quais se sobrepóem, pois há algo comum a elas: um poder violento externo que colapsa o sistema imunológico, o que acaba gerando a experiência de impotência, ou seja, "uma incapacidade capital para salvaguardar a segurança, a vida e a existência." (SYLLA, 2019, p. 112).

Contudo, não bastam os textos há pouco traduzidos de Sloterdijk e Anders: Sylla faz uma apresentaçáo de seus projetos filosóficos, convocando outros escritos e lendo-os desde o crivo do conceito de traumatologia. Em Sloterdijk, a traumatologia se apresenta amplamente ligada a um caráter antropológico com "reivindicações ontológicas e metafísico-cosmológicas" (SYLLA, 2019, p. 115), ao passo que, em Anders, ela se mostra por meio da cooperação dada pelo próprio ser humano à sua aniquilação, uma vez que este desconhece seu crescente esvaziamento existencial e, cada vez mais, entregase ao cotidiano, "à adaptaçáo perfeita ao senso comum e comportamentos estereotipados." (SYLLA, 2019, p. 122).

O texto de João Ribeiro Mendes - Connecting the dots: History, Technology and Work in Günther Anders' The Obsolescence of Man II - está dedicado a analisar a lógica interna do trabalho de Anders, expondo a gênese do caráter totalitário da técnica, do fim do trabalho e do fim da história. Seu mérito, portanto, está na construção do fio que une os três textos há pouco traduzidos. Além disso, o autor avança em direção a outros dois conceitos fundamentais: obsolescência e imperativo tecnológico. Em relação ao primeiro, expõe a ambiguidade nele presente: o conceito não designa só o que já não é, mas também aquilo que já não tem razão de ser e "conjuntamente com 
'homem' - obsolescência do homem - ele, de fato, retrata o desajustamento da humanidade com respeito a seu mundo e, mais terrivelmente, seu anacronismo nesse novo contexto-ambiente" (MENDES, 2019, p. 135). Em relação ao outro, aponta que o imperativo tecnológico, por ser baseado na lógica do "é possível, logo, deve ser feito", confere à tecnologia um poder ilimitado, de tal modo que, de acordo com Anders, já não são as condutas ético-morais da humanidade que dão as diretrizes para o uso dos produtos tecnológicos, senão que são estes mesmos e seus mandamentos que direcionam a ação: "isso significa não apenas que tudo o que é tecnicamente possível deve ser feito, mas também que o que deve ser permitido, obrigatório ou proibido depende apenas do que a tecnologia permite." (MENDES, 2019, p. 136).

O terceiro texto, Blumenberg: Against the Demonization of Technology, assinado por Bernhard Sylla, propóe explicitar por que a perspectiva de Blumenberg pode ser lida como uma crítica às abordagens unilaterais a respeito da técnica, que, por sua vez, exige uma abordagem bi ou até mesmo multilateral, porque "não é só sobre o espírito (Geist), que produz a técnica (Technik), mas também sobre a técnica, que produz espírito.” (SYLLA, 2019, p. 140). Mantendo o estilo de seu outro texto, Sylla traça um percurso que convoca outras obras de Blumenberg, agora não mais para apresentar seu projeto filosófico, mas com a intençáo de mostrar que o próprio Blumenberg faz uma correção/crítica a trabalhos filosóficos precedentes e, ao mesmo tempo, à filosofia da técnica em geral, apontando duas suposições fundamentais distintas como falsas: em primeiro lugar, a posição que assume a técnica e a natureza como antagônicas; "de acordo com essa primeira crítica teórica, o que é unilateral aqui é uma compreensão da técnica segundo a qual a técnica desempenha um papel puramente dissociador e derivativo, no limite, sempre retornando à natureza.” (SYLLA, 2019, p. 141).

Em segundo lugar, a consideração unilateral que entende a técnica como capacidade do homem. Sylla avança justamente em direção a essa segunda crítica, sublinhando sua gênese e seu desdobramento. Para tanto, focaliza a influência de Husserl em Blumenberg, sobretudo, do conceito de mundo da vida, a partir do qual se pode entender a premissa blumenbergiana:

A técnica não é o resultado de uma explicação de certezas pré-teóricas, que se reduz a padrốes de pensamentos naturalistas e, portanto, tanto semiconsciente quanto seminconscientemente explicada, mas a técnica surge já antes da ciência, ou seja, na área pré-teórica de experiência e ação do mundo da vida (Sylla, 2019, p. 142). 
Daí a perspectiva de Blumenberg ser bilateral: ele tende a colocar a interação recíproca do pré-teórico e as motivaçóes fundamentais, de um lado, e os padróes de modelos de interpretação cognitiva, de outro. Em outras palavras: há um posicionamento contrário aos monismos radicais que são otimistas em relação à tecnologia ou tecnofóbicos. Com isso, há uma ambivalência da técnica e da tecnologia, que não deve nem ser demonizada, nem ser só exaltada.

O último texto crítico, de autoria de Felizardo Pedro, tem como título Sloterdijk: da crítica da cinética política à consciência da cidadania da Terra e faz uma introduçáo bastante interessante ao autor, tendo por base duas de suas obras: A mobilização infinita (1989) e O Antropoceno - Estado de um processo à margem da história da Terra? (2016). Para Sloterdijk, o mundo aparece como promessa, devendo o ser humano fazer-se a si mesmo, ou seja, consolidar-se a partir de si mesmo, no mundo no qual foi jogado. Um processo denominado como o "esforço-que-sou-eu", em função do qual o ser humano herda o mundo como promessa. Diante disso, a história surge como a narração dos feitos do ser humano, na tentativa de realizar as promessas recebidas e feitas a si mesmo. O domínio do mundo, então, faz parte da natureza do ser humano, que, com isso, cria para si uma segunda natureza: a cultura.

Contudo, há diferentes perspectivas de "domínio da Terra": a do cidadão do mundo, pautada no eu-para-a-morte, permeado pela transitoriedade e pelo não sentido da existência, e a do cidadão da Terra, pautada no eu-sou-pornascimento, o qual, sabendo de sua condição ontológica de ser-que-veio-aomundo, assume a Terra como destino. A partir disso, ao apresentar a diferença entre alotécnica e homeotécnica, o autor justifica por que a perspectiva de Sloterdijk pode ser avaliada como otimista em relação à técnica, bem como por que ainda é necessário dar espaço para que ela seja utilizada para o bem.

Por fim, recomenda-se a leitura de Tecnofilosofia líquida: Anders, Blumenberg e Sloterdijk, obra de domínio público e de acesso gratuito, não só porque ela dá a conhecer textos de autores ainda pouco explorados em língua portuguesa, mas também porque ela não trata só de autores contemporâneos: toda a tradição filosófica é por ela convocada, uma vez que a ideia mesma de $\tau \varepsilon ́ \chi v \eta$ é uma das heranças deixadas pela Antiguidade Grega à filosofia como um todo. Ademais, ao trazer um conjunto de textos críticos, os organizadores sinalizam rumos possíveis a investigaçôes futuras, abrindo possibilidades e, por que não, servindo de porta de entrada ao(à) leitor(a) para este tema tão em voga nas discussóes filosóficas: a pertinência da técnica e da tecnologia. 
PROVINCIATTO, L. G.

\section{REFERÊNCIA}

MENDES, J. R.; SYLLA, B. J. Tecnofilosofia líquida: Anders, Blumenberg e Sloterdijk. Braga: Centro de Ética, Política e Sociedade, 2019. 